\title{
Metallomics
}

Check for updates

Cite this: Metallomics, 2017 9, 1447

Received 21st August 2017 Accepted 13th September 2017

DOI: 10.1039/c7mt00244k

rsc.li/metallomics

\section{Subcellular compartmentalisation of copper, iron, manganese, and zinc in the Parkinson's disease brain $\dagger$}

\author{
Sian Genoud, (D) ${ }^{a}$ Blaine R. Roberts, ${ }^{b}$ Adam P. Gunn, ${ }^{b}$ Glenda M. Halliday, ${ }^{\text {acd }}$ \\ Simon J. G. Lewis, ${ }^{\text {aef }}$ Helen J. Ball, ${ }^{9}$ Dominic J. Hare (D) ${ }^{\text {bhi }}$ and Kay L. Double*a
}

\begin{abstract}
Elevated iron and decreased copper levels are cardinal features of the degenerating substantia nigra pars compacta in the Parkinson's disease brain. Both of these redox-active metals, and fellow transition metals manganese and zinc, are found at high concentrations within the midbrain and participate in a range of unique biological reactions. We examined the total metal content and cellular compartmentalisation of manganese, iron, copper and zinc in the degenerating substantia nigra, disease-affected but nondegenerating fusiform gyrus, and unaffected occipital cortex in the post mortem Parkinson's disease brain compared with age-matched controls. An expected increase in iron and a decrease in copper concentration was isolated to the soluble cellular fraction, encompassing both interstitial and cytosolic metals and metalbinding proteins, rather than the membrane-associated or insoluble fractions. Manganese and zinc levels did not differ between experimental groups. Altered Fe and $\mathrm{Cu}$ levels were unrelated to Braak pathological staging in our cases of late-stage (Braak stage $\mathrm{V}$ and $\mathrm{VI}$ ) disease. The data supports our hypothesis that regional alterations in $\mathrm{Fe}$ and $\mathrm{Cu}$, and in proteins that utilise these metals, contribute to the regional selectively of neuronal vulnerability in this disorder.
\end{abstract}

\section{Introduction}

The brain contains some of the highest concentrations of iron $(\mathrm{Fe})$, copper $(\mathrm{Cu})$, zinc $(\mathrm{Zn})$ and manganese $(\mathrm{Mn})$ in the human body. ${ }^{1}$ These metals are responsible for numerous cellular functions including synaptic transmission, myelinogenesis, energy production and regulation of oxidative stress. Many of these biochemical processes rely on metals for transfer of electrons via redox chemistry, neuronal excitation, protein

\footnotetext{
${ }^{a}$ Discipline of Biomedical Science and Brain and Mind Centre, Sydney Medical School, The University of Sydney, Camperdown, NSW 2006, Australia.

E-mail: kay.double@sydney.edu.au; Tel: +61 291144294

${ }^{b}$ The Florey Institute of Neuroscience and Mental Health, The University of Melbourne, Parkville, VIC 3052, Australia. E-mail: dominic.hare@florey.edu.au; Tel: +61 390359549

${ }^{c}$ Neuroscience Research Australia, Randwick, NSW 2031, Australia

${ }^{d}$ School of Medical Sciences, University of New South Wales, NSW 2052, Australia

${ }^{e}$ Healthy Brain Ageing Program, University of Sydney, NSW 2006, Australia

${ }^{f}$ Royal Prince Alfred Hospital, Camperdown, NSW 2050, Australia

${ }^{g}$ Bosch Institute, University of Sydney, Camperdown, NSW 2006, Australia

${ }^{h}$ Elemental Bio-imaging Facility, University of Technology Sydney, Broadway, NSW 2007, Australia

${ }^{i}$ Department of Pathology, The University of Melbourne, Parkville, VIC 3052, Australia

$\dagger$ Electronic supplementary information (ESI) available. See DOI: 10.1039/ $\mathrm{c} 7 \mathrm{mt} 00244 \mathrm{k}$
}

structure and enzymatic function. ${ }^{2}$ Alterations in the levels and distribution of these transition metals are consistently reported in the Parkinson's disease brain, ${ }^{3,4}$ with the best documented change being elevated levels of Fe in the substantia nigra pars compacta ( $\mathrm{SNc}$ ). Abnormal deposition of $\mathrm{Fe}$ in the Parkinson's disease brain was first reported in $1924 ;^{5}$ since then numerous studies have identified significantly increased $\mathrm{Fe}$ levels within vulnerable brain regions in this disorder beyond those observed in healthy aged-matched brains. ${ }^{6,7}$

Additionally, a concomitant decrease in $\mathrm{Cu}$ concentration has also been reported in degenerating regions of the Parkinson's disease brain, ${ }^{8,9}$ while data regarding $\mathrm{Zn}$ levels are conflicting. ${ }^{3,10}$ Occupational exposure to $\mathrm{Mn}$ alone has been demonstrated to cause parkinsonism, ${ }^{11}$ highlighting the necessity for tight $\mathrm{Mn}$ regulation in the brain.

To date, most studies have described regional alterations in total metal levels (typically Fe) in whole tissue samples. ${ }^{3,6,12,13}$ While such studies are useful to identify the neuroanatomical location of changes in specific metals, alterations at the cellular and subcellular level in the Parkinson's disease brain are less well understood. Determining the cellular compartment in which these changes occur may aid in determining the underlying cause of these alterations, and the pathological effects subsequently produced in their subcellular environment. 
In this study, we examined the subcellular compartmentalisation of $\mathrm{Mn}, \mathrm{Fe}, \mathrm{Cu}$ and $\mathrm{Zn}$ in three regions of the Parkinson's disease brain displaying varying degrees of neurodegeneration and proteinopathology. We separated tissue samples into three fractions representing the 'soluble', 'membrane-associated' and 'insoluble' tissue components respectively, to identify the specific cellular compartment in which metal alterations are most marked. We also examined whether total metal levels were altered according to late-stage Braak pathology.

\section{Experimental}

\section{Ethics, consent and permissions}

Human ethics for this study was granted by the University of Sydney (ID: 2015/202) and the University of Melbourne (ID: 1136882).

\section{Human brain tissue}

In total, fresh frozen human post-mortem brain tissue was obtained from 13 Parkinson's disease (PD) subjects and 11 age-matched controls (Ctrl). Three specific regions were analyzed: substantia nigra (SN; encompassing both pars reticulata and pars compacta regions; $n_{\mathrm{PD}}=9, n_{\mathrm{Ctrl}}=8$ ), fusiform gyrus (FUS; $n_{\mathrm{PD}}=9, n_{\mathrm{Ctrl}}=8$ ) and occipital cortex (OCx; $\left.n_{\mathrm{PD}}=11, n_{\mathrm{Ctrl}}=11\right)$ were obtained from the New South Wales and Sydney Brain Banks. Demographic details for these cases are shown in Table 1. All Parkinson's disease cases were receiving levodopa at the time of death; other anti-parkinsonian medications prescribed ( $n=1$ case per medication) were a COMT inhibitor, a MAO inhibitor, a drug trial of Sarizotan (a 5- $\mathrm{HT}_{1 \mathrm{~A}}$ agonist and $\mathrm{D}_{2}$ dopamine receptor antagonist), and a dopamine agonist.

\section{Tissue preparation}

Tissue preparation was adapted from our previously published methods. ${ }^{14-17}$ Tissue samples (11.6-22.5 mg wet weight) were homogenised with a hand-held dounce (Omni BioMasher, Georgia, USA) in $3 \times$ tissue weight of Tris buffered saline (TBS: 50 mM Tris; $150 \mathrm{mM} \mathrm{NaCl}$; pH 8.0) containing EDTA free protease inhibitors (Roche, NSW, Australia). Samples were centrifuged at $16000 \mathrm{~g}$ for $15 \mathrm{~min}$ at $4{ }^{\circ} \mathrm{C}$ before the supernatant fraction was collected and stored at $-80{ }^{\circ} \mathrm{C}$. This was termed the 'soluble fraction', and represented all cytosolic proteins and the interstitium. The remaining tissue pellet was resuspended in $3 \times$ tissue weight of urea buffer ( $7 \mathrm{M}$ urea; $2 \mathrm{M}$ thiourea, $4 \%$ 3-[(3-cholamindopropyl) dimethylammonio]-1-propanesulfonate (CHAPS); $30 \mathrm{mM}$ Bicine; pH 8.5; Sigma, NSW, Australia) and centrifuged $16000 \mathrm{~g}$ for $30 \mathrm{~min}$ at $4{ }^{\circ} \mathrm{C}$ and the resultant supernatant was collected and stored at $-80{ }^{\circ} \mathrm{C}$. This was termed the 'membrane fraction', representing both membrane-bound proteins and those encased within cellular organelles. The final pellet was resuspended in $3 \times$ tissue weight of $70 \%$ formic acid overnight before being centrifuged at $16000 \mathrm{~g}$ for $30 \mathrm{~min}$ and the resultant supernatant collected and stored at $-80{ }^{\circ} \mathrm{C}$. This was termed the 'insoluble fraction', and represented all material not previously extracted. No observable material remained following the final preparation step.

\section{Inductively coupled plasma-mass spectrometry (ICP-MS)}

ICP-MS analysis was performed according methods previously reported. ${ }^{18}$ Each fraction was randomised before being thawed on ice and diluted 1:20 with 1\% $\mathrm{HNO}_{3}$ (v/v; Suprapur grade, Merk Millipore, VIC, Australia) prior to analysis. Total metal

Table 1 Demographic details for experimental tissue. $\mathrm{PD}=$ Parkinson's disease; $\mathrm{PMI}=$ post-mortem interval; $\mathrm{SEM}=$ standard error of $\mathrm{mean} ; \mathrm{NA}=$ not available

\begin{tabular}{|c|c|c|c|c|c|c|c|}
\hline Case & Age & Sex & Disease duration & Primary cause of death & Tissue $\mathrm{pH}$ & Braak staging of $\mathrm{PD}$ & PMI \\
\hline PD1 & 82 & M & 5 & Cardiorespiratory failure & 6.72 & $\mathrm{~V}$ & NA \\
\hline PD2 & 82 & $\mathrm{~F}$ & 15 & Cerebrovascular accident & 6.95 & $\mathrm{~V}$ & NA \\
\hline PD3 & 83 & $\mathrm{~F}$ & 14 & Pneumonia & 6.69 & $\mathrm{~V}$ & 7 \\
\hline PD4 & 69 & M & 17 & Bronchopneumonia & 5.99 & $\mathrm{~V}$ & NA \\
\hline PD5 & 90 & M & 7 & Respiratory failure & 6.25 & $\mathrm{~V}$ & NA \\
\hline PD6 & 85 & $\mathrm{~F}$ & 17 & Cerebrovascular accident & 6.58 & $\mathrm{~V}$ & 26 \\
\hline PD7 & 74 & M & 8 & Cerebrovascular accident & 5.86 & VI & NA \\
\hline PD8 & 83 & $\mathrm{~F}$ & 14 & Cardiorespiratory failure & 6.2 & $\mathrm{~V}$ & 32 \\
\hline PD9 & 79 & M & 17 & Septicaemia & 6.7 & VI & 42 \\
\hline PD10 & 88 & M & 23 & Cardiorespiratory failure & 6.6 & $\mathrm{~V}$ & 5 \\
\hline PD11 & 82 & M & 22 & Cardiorespiratory failure & 6.4 & VI & 19 \\
\hline PD12 & 82 & M & 8 & Cardiorespiratory failure & 6.3 & VI & 22 \\
\hline PD13 & 77 & M & 15 & Aspiration pneumonia & 6.4 & $\mathrm{~V}$ & 15 \\
\hline Mean (SEM) & $81.23(2.36)$ & $9 M: 4 F$ & $14(2.37)$ & 一 & $6.43(0.56)$ & $9 V: 4 V I$ & $21(3.52)$ \\
\hline Ctrl1 & 85 & $\mathrm{~F}$ & - & Pneumonia & 6.4 & - & 23 \\
\hline Ctrl2 & 79 & M & - & Pulmonary embolism & 6.7 & - & 8 \\
\hline Ctrl3 & 84 & $\mathrm{~F}$ & - & Cardiorespiratory failure & 6.5 & - & 6 \\
\hline Ctrl4 & 89 & $\mathrm{~F}$ & - & Metastatic adenocarcinoma & 6 & - & 23 \\
\hline Ctrl5 & 91 & M & - & Cardiorespiratory failure & 5.9 & - & 13 \\
\hline Ctrl6 & 89 & M & - & Cardiorespiratory failure & 6.1 & - & 33 \\
\hline Ctrl7 & 102 & $\mathrm{~F}$ & - & Acute renal failure & 5.92 & - & NA \\
\hline Ctrl8 & 89 & M & - & Cardiorespiratory failure & 6.7 & - & 22 \\
\hline Ctrl9 & 88 & $\mathrm{~F}$ & - & Cardiorespiratory failure & 6.2 & - & 31 \\
\hline Ctrl10 & 49 & M & - & Cardiorespiratory failure & 6.5 & - & 47 \\
\hline Ctrl11 & 41 & M & - & Cardiorespiratory failure & 7 & - & 48 \\
\hline Mean (SEM) & $80.55(4.30)$ & $6 M: 5 F$ & - & & $6.36(0.60)$ & - & $25.4(3.82)$ \\
\hline
\end{tabular}


levels in each fraction were measured using an Agilent Technologies $7700 \times$ ICP-MS system with a Teflon MiraMist concentric nebuliser and Scott-type double-pass spray chamber (Glass Expansion, VIC, Australia). Helium ( $3 \mathrm{~mL} \mathrm{~min}^{-1}$ ) was used as a collision gas for removal of polyatomic interferences. Measured mass-to-charge $(\mathrm{m} / \mathrm{z})$ ratios were $55(\mathrm{Mn}), 56(\mathrm{Fe})$, $63(\mathrm{Cu})$ and $64(\mathrm{Zn})$. External calibration was performed using multi-element standards (Sigma) diluted in $1 \% \mathrm{HNO}_{3}$ and yttrium (Y; $m / z=89$; Accustandard, Connecticut, USA) was used as reference element via online introduction with a Teflon T-piece.

\section{Statistical analysis}

Statistical analyses were performed using Prism v6.0h (GraphPad, California, USA) for absolute metal levels, and SPSS v22.0 (IBM), and CoDaPack for compositional data. ${ }^{19}$ A Student's two-tailed $t$-test was performed to confirm age-matching, and a chi-squared test for sex-matching and comparing Braak stage. Tissue samples were background corrected according to their respective buffers, adjusted for dilution factors and standardised against original wet sample weights to obtain concentrations in microgram per gram $\left(\mu \mathrm{g} \mathrm{g}^{-1}\right)$ of wet tissue weight. Samples below instrument limit of detection were excluded from analysis. ${ }^{20}$ Outliers were identified using the combined robust regression and outlier removal (ROUT) method with a maximum false discovery rate of $5 \% .^{21}$ Total metal levels were calculated as the sum of the metal content in each fraction. Metal concentrations in each fraction for control and Parkinson's disease groups were compared using one-way analysis of variance (ANOVA) followed by Sidak post hoc correction for multiple comparisons, or a Student's two-tailed $t$-test, as noted in the results. For analysis of metal distribution within fractions between control and Parkinson's disease groups, centered-transformations ${ }^{22}$ were performed in CoDaPack and the subsequent compositional data was compared using multi-variate ANOVA in SPSS. All charts were drawn using Prism. A significant difference was defined as $p<0.05$.

\section{Results}

Regional distribution of total metal levels in the healthy and diseases substantia nigra, occipital cortex and fusiform gyrus

Copper concentrations were regionally varied in the healthy brain with significantly higher levels of $\mathrm{Cu}$ in the healthy $\mathrm{SN}$ compared with the OCx and FUS $(+153 \%$ vs. OCx, $p<0.01$; $+233 \%$ vs. FUS, $p<0.001$; one-way ANOVA; Fig. 1a). The concentration of $\mathrm{Cu}$ in the Parkinson's disease SN was approximately half that of control SN $(-54 \%, p<0.05$; Student's twotailed $t$-test), resulting in the significant difference between nigral $\mathrm{Cu}$ concentration and that in the OCx and FUS observed in the healthy brain being absent in Parkinson's disease tissue.

As expected, Fe was significantly higher in the healthy SN compared with FUS $(+106 \%, p<0.05)$ and OCx $(+61 \%, p<$ 0.05; Fig. 1b). In Parkinson's disease brain, this greater concentration of nigral Fe was more pronounced, with nigral concentrations representing more than twice $(+210 \%)$ that of the
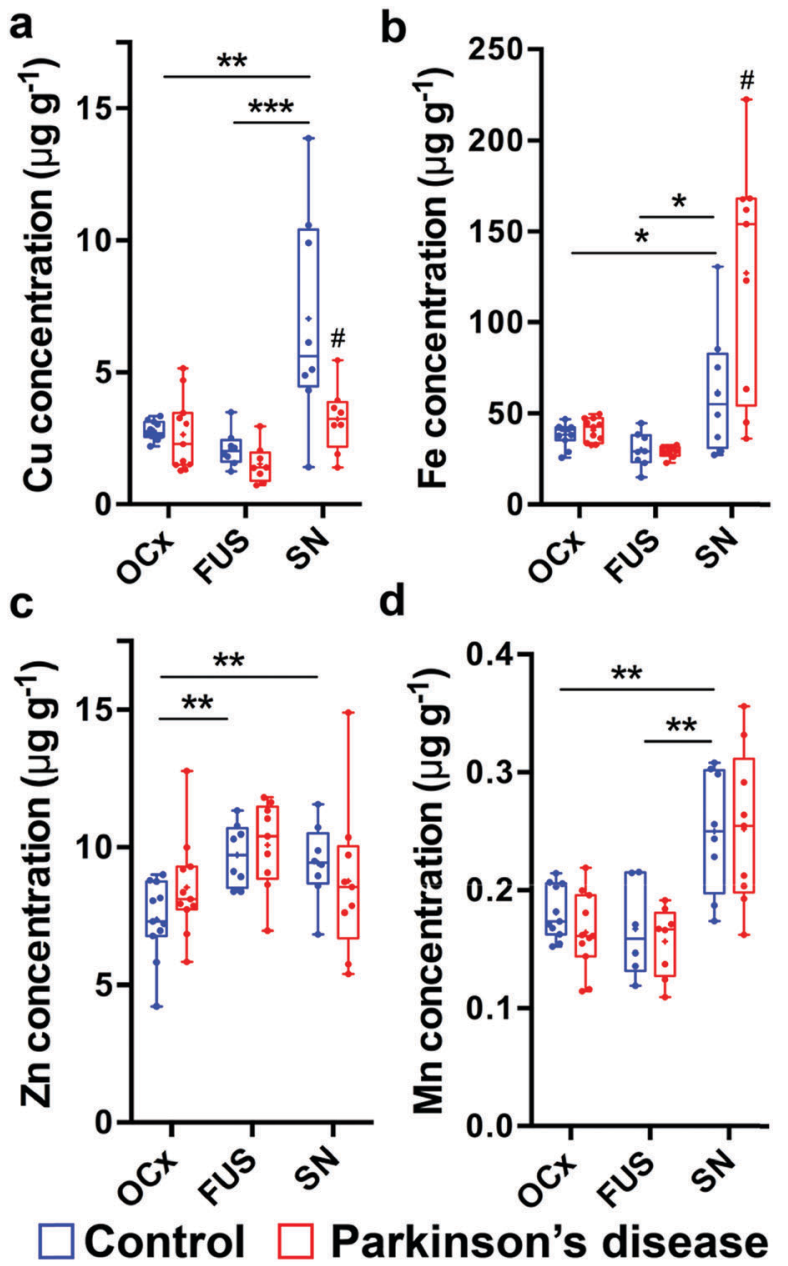

Fig. 1 Biometal distribution in the occipital cortex (OCX) fusiform gyrus (FUS) and substantia nigra (SN) of healthy aged controls and Parkinson's disease. (a) The concentration of $\mathrm{Cu}$ in control tissue was highest in the SN, though in the Parkinson's disease brain $\mathrm{Cu}$ concentrations decreased to levels equivalent to that in the control SN. (b) In control brains, the concentration of $\mathrm{Fe}$ in the $\mathrm{SN}$ was also significantly higher than the FUS and OCx regions. Iron concentrations were further elevated in the Parkinson's disease SN. (c) Zinc concentrations were lowest in the OCx, and (d) Mn was highest within the SN. Neither Zn or Mn were altered in the Parkinson's disease OCx, FUS or SN. * $p<0.05,{ }^{* *} p<0.01$, ${ }^{\star * *} p<0.001$ (vs. control regions); \# $p<0.05$, \#\#\# $p<0.001$ (control vs. Parkinson's disease $\mathrm{SN}$ ). All concentrations are $\mu \mathrm{g} \mathrm{g}^{-1}$ wet weight of tissue.

Parkinson's disease OCx $(p<0.001)$ and three times $(+338 \%)$ that of the Parkinson's disease FUS $(p<0.001$; all one-way ANOVA), reflecting an accumulation of Fe within the Parkinson's disease SN $(+105 \%$ vs. control SN, $p<0.05$; Student's two-tailed $t$-test). Both the Parkinson's disease OCx and FUS did not show significant changes in Fe concentration when compared to healthy controls. Zinc levels were unaltered in the Parkinson's disease brain in the three regions analysed, though the control OCx contained less $\mathrm{Zn}$ than both the healthy FUS $(-24 \%$, $p<0.01)$ and SN $(-22 \%, p<0.01$; one-way ANOVA; Fig. 1c). Manganese concentrations were significantly higher in both healthy and diseased SN, compared with the FUS $(+40 \%, p<0.01)$ and OCx $(+32 \%, p<0.01$; Fig. 1d). Like $\mathrm{Cu}$ and Fe, Mn was more 
concentrated in the healthy SN than the OCx $(+38 \%, p<0.01)$ and FUS ( $+49 \%, p<0.01$; one-way ANOVA; Fig. S1b, ESI $\dagger$ ), though no changes were observed within regions according to disease state.

\section{Transition metal alterations in cellular compartments of the Parkinson's disease substantia nigra}

In the Parkinson's disease $\mathrm{SN}$, the decreased $\mathrm{Cu}$ concentration was confined to the soluble faction $(-53 \% ; p<0.01$; Fig. 2a). No detectable $\mathrm{Cu}$ was observed in the insoluble fraction in control brains, but was detected in four of seven of the Parkinson's disease SN samples. Similarly, in this region, we observed elevations in total Fe levels in the Parkinson's disease
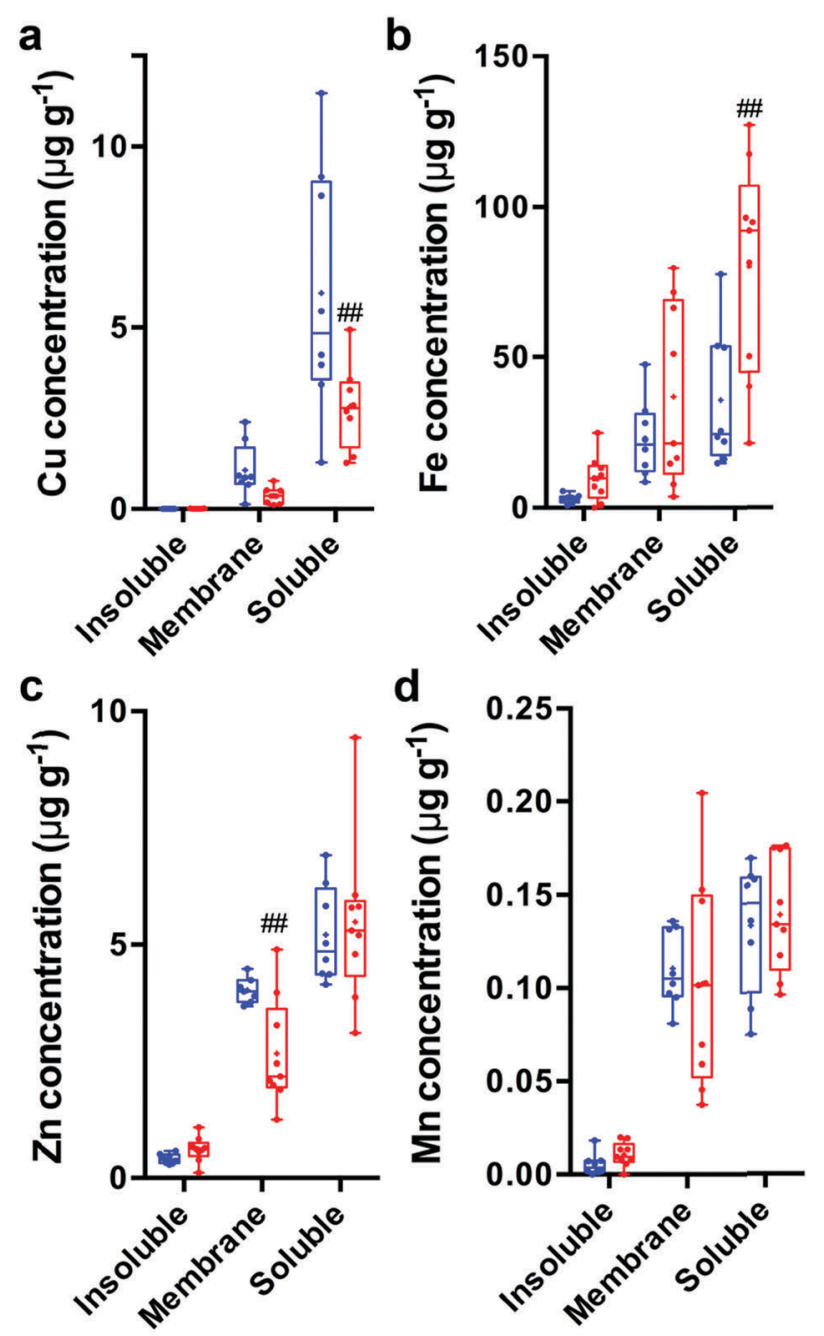

\section{Control $\square$ Parkinson's disease}

Fig. 2 Within both the Parkinson's disease and control SN, the majority of (a) $\mathrm{Cu}$, (b) Fe, and (c) Zn was present in the soluble fraction, followed by the membrane and insoluble fractions, respectively. (d) For Mn, equivalent amounts were distributed between the soluble and membrane-bound fractions. In the Parkinson's disease SN, the observed reduction in total $\mathrm{Cu}$ and increase in total Fe are confined to the soluble fraction, and a decrease in $\mathrm{Zn}$ within the membrane-associated fraction was also observed, although total $\mathrm{Zn}$ levels were not altered. \#\# $p<0.01$, (control vs. Parkinson's disease). All concentrations are $\mu \mathrm{g} \mathrm{g}^{-1}$ wet weight of tissue.
SN that were also attributable to the soluble fraction $(+124 \%$, $p<0.01$; Fig. 2b). Although total zinc levels were unchanged in the Parkinson's disease SN, the membrane-associated fraction exhibited a significant decrease in this metal confined to this brain region $(-34 \% ; p<0.01$; Fig. 2c; Student's two-tailed $t$-tests). Manganese levels did not differ in any fraction between controls and Parkinson's disease tissue (Fig. 2d).

The percentage distribution of $\mathrm{Cu}, \mathrm{Fe}, \mathrm{Zn}$ and $\mathrm{Mn}$ (Table 2) in the insoluble, membrane-associated and soluble fraction was not altered in any brain region between the healthy agedcontrol and Parkinson's disease brain. This suggests that intrinsic metal dyshomeostasis (i.e. decreased $\mathrm{Cu}$ and increased $\mathrm{Fe}$ levels) is not merely a redistribution of available metals, but instead remains distributed equivalently, with only absolute levels markedly altered in the Parkinson's disease SN.

\section{Are altered metal levels in the Parkinson's disease substantia nigra related to late Braak staging?}

All cases assessed were late-stage Parkinson's disease, and at post mortem all were classified as either Braak stage $\mathrm{V}$ and four stage VI, per the established pathological criteria. ${ }^{23}$ No significant difference in total metal levels were observed in any of Parkinson's disease tissue from three regions assessed, other than a slight, non-significant decrease in Fe levels in the FUS $(-12 \%, p=0.055)$ (Fig. S2, ESI $\dagger$ ). A significantly higher Fe concentration in the membrane fraction of the $\mathrm{SN}(+392 \%$; $p<0.05$ ), and lower Fe concentration in the soluble phase of the OCx $(-31 \% ; p<0.01$; Fig. 3$)$, was observed in stage VI cases compared to stage $\mathrm{V}$, though the small sample size and large variance within the $\mathrm{SN}$ suggests these data should be interpreted with caution (see Discussion).

\section{Discussion}

The regions selected in this study represent three distinct pathological states in the Parkinson's disease brain. The SN is the primary site of dopaminergic neurodegeneration which results in the clinical movement disorder. ${ }^{24}$ The dopaminergic FUS displays synucleinopathy and atrophy ${ }^{25}$ and is associated with visual hallucinations and Parkinson's disease with dementia, albeit in the absence of neurodegeneration. ${ }^{26}$ Finally, the OCx represents an 'internal control', in that this region exhibit neither Lewy pathology nor degeneration in Parkinson's disease.

The region-specific distribution of total $\mathrm{Cu}$ and $\mathrm{Fe}$ in the three measured regions of the healthy brain we report here was consistent with previous reports. ${ }^{27-29}$ In the Parkinson's disease brain, significant differences in metal levels were confined to the $\mathrm{SN}$, specifically a decrease in total $\mathrm{Cu}$ and increase in total $\mathrm{Fe}$. Our group has previously reported a $-45 \%$ change in total SN Cu levels, ${ }^{8}$ while others have reported similar decreases $\left(-51 \%\right.$ by Ayton et al. ${ }^{30}$ and -34 to $45 \%$ in Dexter et al.'s landmark study from $1989^{31}$ ). Increased nigal Fe is a well-established feature of Parkinson's disease from numerous observational studies, and was further supported by a recent metaanalysis of these reports. ${ }^{7}$ 
Table 2 Percentage distribution of $\mathrm{Cu}, \mathrm{Fe}, \mathrm{Zn}$ and $\mathrm{Mn}$ in insoluble, membrane-bound and soluble fractions of control and Parkinson's disease brain. All data mean $\pm 1 S D$

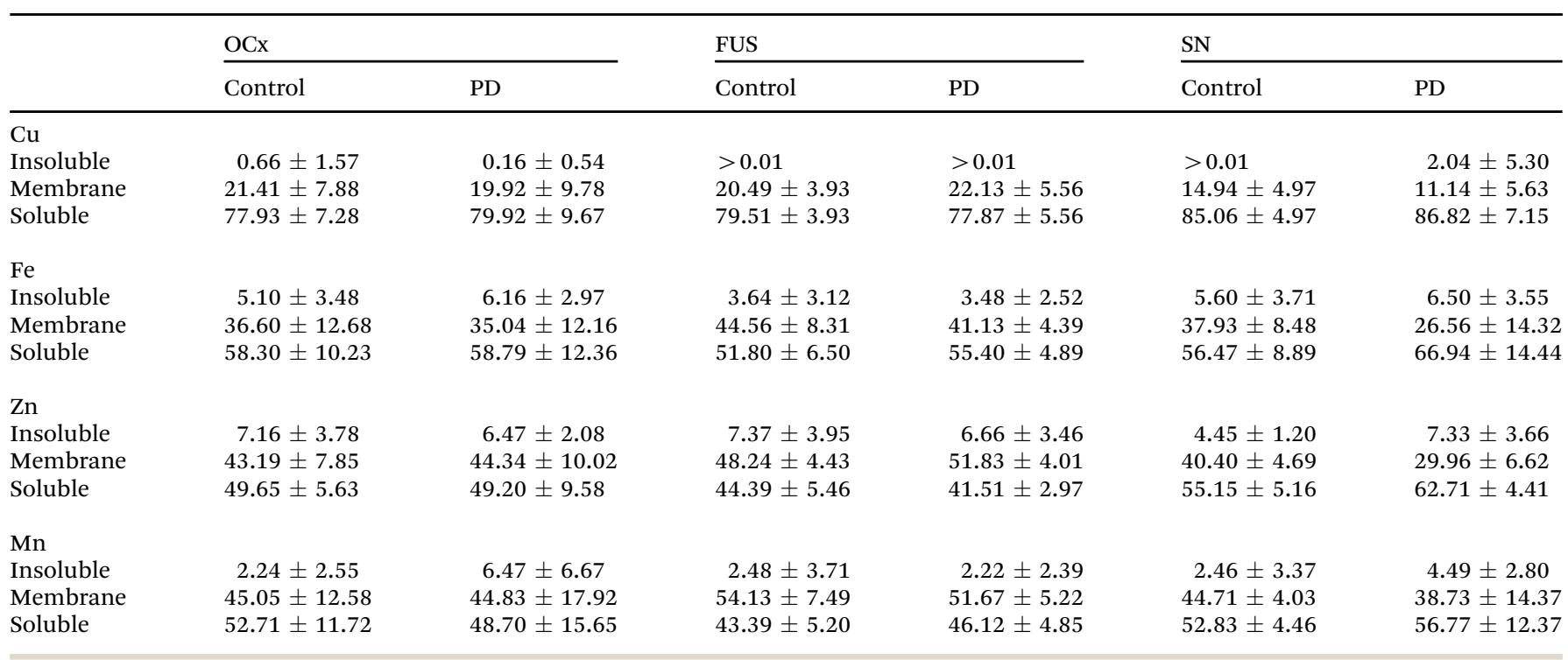

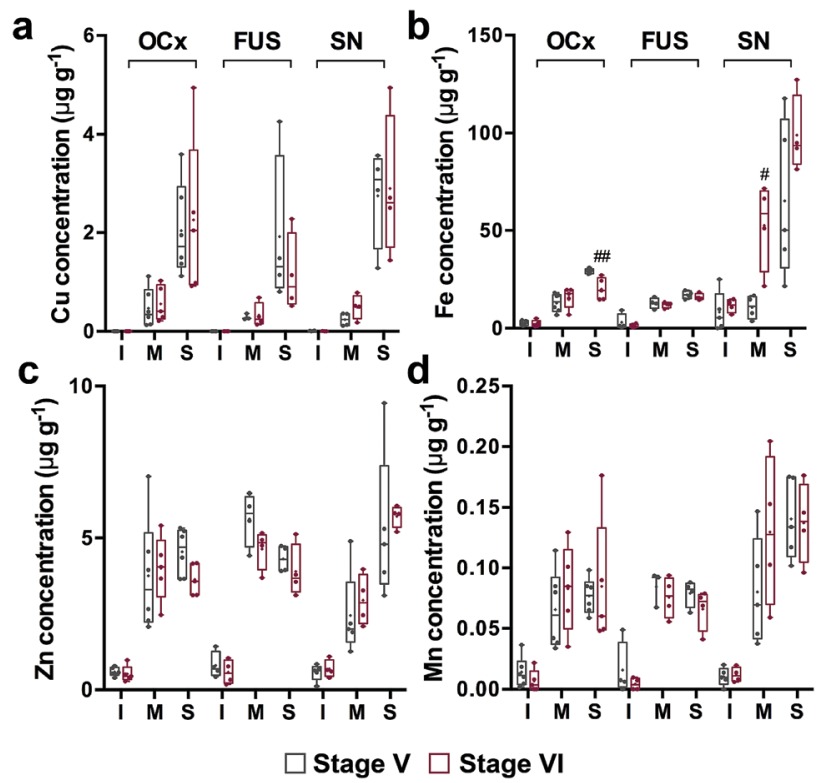

Fig. 3 Concentration of (a) $\mathrm{Cu}$, (b) $\mathrm{Fe}$, (c) $\mathrm{Zn}$, (d) and $\mathrm{Mn}$ in cellular fractions according to Braak staging in the Parkinson's disease OCx, FUS and SN. Only Fe shows any significant change in concentration between Braak stage $\mathrm{V}$ and $\mathrm{VI}$, with a decrease in the soluble fraction of $\mathrm{OCx}$ and increase in the membrane-bound fraction in the $\mathrm{SN}$ in stage VI. \# $p<0.05$; $\# \# p 0.01 . I=$ insoluble, $M=$ membrane, $S=$ soluble.

For the first time, we have isolated these changes to the 'soluble' cellular fraction, which represents the interstitium and cytoplasm. ${ }^{17}$ Within this fraction are aqueous proteins including antioxidant enzymes, as well as free metals present in the tissue. Membrane-associated metal-protein complexes likely comprises of protein channels and pumps involved in transfer of metals across cell plasma membrane, and metals found within membrane-bound organelles. Despite moderate metal concentrations in the membrane-associated fractions
( $\sim 35 \%$ total $\mathrm{Fe}, \sim 20 \%$ total $\mathrm{Cu}$ and $\sim 45 \%$ total $\mathrm{Zn}$; Table 2 ), similar changes in $\mathrm{Cu}$ and $\mathrm{Fe}$ observed in the soluble fraction were not observed. Metal-protein interactions for the purpose of transport across the plasma membrane or directed transport within the cells are likely to be transient however, and thus only a small proportion of membrane-associated transport proteins are likely to have been metal-bound at the time of extraction. A more stable pool of metals may be represented by plasma bound organelles such as mitochondria, which internalise Fe, $\mathrm{Cu}, \mathrm{Mn}$ and $\mathrm{Zn}$ for both specific biological function or the synthesis of metalloproteins such as Fe-sulfur complexes or cytochrome $c$ oxidase. Although mitochondrial dysfunction, and resulting effects on metal levels, are proposed to contribute to neuronal death in Parkinson's disease, ${ }^{32}$ the fractionation technique used here may have masked subtle changes in mitochondrial metal levels and specific isolation of mitochondria from other membrane-encapsulated metals in Parkinson's disease and control samples would be required.

The purpose of the current study was to establish the specific subcellular compartments in which known alterations in biometals occur. In doing so, we can then narrow the scope of future proteomic studies targeting these specific subcellular compartments using high-throughput shotgun proteomics methods, ${ }^{33}$ which are currently underway in our laboratory. In addition, as both a-synuclein and SOD1 are demonstrated to aggregate in Parkinson's disease,${ }^{34}$ determining the subcellular fraction where these metal changes occur allows us to then identify whether these alterations are associated with the soluble forms of these proteins, or the aggregated form which would reside in the insoluble fraction.

The insoluble component of SN homogenates represented only a small proportion of total metal levels and we observed no changes in metals in this fraction in any brain region. Within the healthy $\mathrm{SN}$, the insoluble fraction is likely to comprise of the insoluble macromolecules neuromelanin and lipofuscin, 
cellular pigments which accumulate in the aging human brain $^{35}$ and associate with metals, including $\mathrm{Fe}, \mathrm{Cu}, \mathrm{Zn}$ and Mn. ${ }^{28,29,35,36}$ These pigments are highly abundant in the aged human brain, for example neuromelanin fills almost $50 \%$ of the volume of SN dopaminergic soma in individuals in their eighth decade of life. ${ }^{37}$ Using in situ subcellular chemical imaging, we have previously reported increased $\mathrm{Fe}$ and decreased $\mathrm{Cu}$ associated with neuromelanin in the SNc neurons from the Parkinson's disease brain, ${ }^{8}$ although here these changes may have been obscured by the presence of other equally abundant, but not disease-related, metal-binding biomolecules, such as lipofuscin, in this tissue fraction. The insoluble fraction of the Parkinson's disease SN is also likely to include a smaller proportion by mass of small insoluble proteinaceous deposits, including Lewy bodies ${ }^{24}$ and SOD1 aggregates. ${ }^{34}$ While metals have been suggested to induce $\alpha$-synuclein oligomerisation and aggregation in vitro, ${ }^{38}$ it is unclear whether Lewy bodies retain metal ions. We recently demonstrated that SOD1 aggregates recently identified in Parkinson's disease share pathological similarities with the deposited protein in familial amyotrophic lateral sclerosis spinal cord and $\mathrm{SN}^{34}$ and this class of aggregate has been shown to be deficient in $\mathrm{Cu}^{39}$ The different populations of insoluble protein aggregates in degenerating regions of the Parkinson's disease brain may thus display metal associations that differ from that in the normal soluble protein, a hypothesis that could be tested using, for example, biochemical imaging analysis at the single aggregate level.

The disease-affected, but non-degenerating, FUS exhibited no evidence of perturbed metal levels supporting the hypothesis that metal dyshomeostasis, and associated oxidative stress, are restricted to specific degenerating regions of the Parkinson's disease brain. ${ }^{40,41}$ This poses an interesting question regarding the toxicity of synucleinopathy pathways in brain regions where metal levels are normal. In vitro evidence suggests that metal ions interact with $\alpha$-synuclein to promote oxidative stress and neuronal death, ${ }^{42}$ however, we report here that the FUS, which features accumulation of $\alpha$-synuclein in Parkinson's disease in the absence cell death does not exhibit altered metal levels. Maintenance of metal homeostasis may thus be sufficient to mitigate cell death, despite proteinopathy. Further, no measurable increase in Fe within the FUS compared to control implies that increased oxidative stress arising from the Fe/dopamine/ $\alpha$-synuclein axis does not occur within this brain region. ${ }^{43}$ The FUS has recently been established as a site of marked glial activation in Parkinson's disease ${ }^{44}$ which suggests that neuroinflammatory processes are not contributing to an increased amount of total Fe.

Given that many transition metals pose a significant oxidative threat to tissues, the proportion of free, or 'labile' metals present is limited and highly regulated. ${ }^{45}$ In the healthy cell, the majority of $\mathrm{Fe}$ is present in the cytoplasm as the reduced ferric species ${ }^{46}$ and as part of a redox-silenced protein complex, which may utilise the metal for a specific biological function (e.g. Fe-catalysed activity of aromatic amino acid hydroxylases) or provide a mechanism for safe storage (e.g. ferritin). For instance, labile Fe present in a typical cell is estimated to account for around $3-5 \%$ of total cellular iron $\left(\sim 1-3 \mu \mathrm{g} \mathrm{g}{ }^{-1}\right)$, and labile $\mathrm{Cu}$ in the human cortex has been empirically measured at a similar concentration. ${ }^{47}$

Elevated Fe in the Parkinson's disease SN has long been associated with neurotoxicity via various mechanisms such as oxidative, ${ }^{48}$ ferroptosis, ${ }^{49}$ and deleterious interactions between dopamine and $\mathrm{Fe}^{43,50}$ It has long been argued whether $\mathrm{Fe}$ accumulation in the Parkinson's disease SN is a potential upstream cause of disease $\mathrm{s}^{51,52}$ or merely an effect of inflammation. ${ }^{53,54}$ Despite this however, both inflammatory responses, and increased intraneuronal $\mathrm{Fe}$ and altered intracellular Fe-regulating systems have been implicated Fe dyshomeostasis in neuronal loss in the PD brain. The importance of brain Fe changes in the aetiology of Parkinson's disease may best be demonstrated by removal of excess levels of this metal. Iron chelation therapy using deferiprone to lower brain iron levels has showed promise in pilot clinical studies ${ }^{55}$ and is now in Phase IIa trials in recentlydiagnosed Parkinson's disease patients (FAIR PARK II; ClinicalTrials.gov identifier: NCT02655315).

Dysfunction in a range of Fe regulatory pathways have been associated with its neuronal accumulation in Parkinson's disease ${ }^{56}$ which we show here is primarily present in the soluble tissue fraction. These changes include decreased activity of the ferroxidase ceruloplasmin, an extracellular protein responsible for reducing $\mathrm{Fe}$ (II) to $\mathrm{Fe}$ (III) for transferrin loading after neuronal export, ${ }^{57}$ due to a lack of its required $\mathrm{Cu}$ cofactor. ${ }^{30}$ Modulation of ceruloplasmin has been proposed as a potential therapeutic strategy for Parkinson's disease. ${ }^{58}$

An additional cuproprotein potentially affected by a reduction in cytosolic $\mathrm{Cu}$ is the antioxidant conferring enzyme superoxide dismutase-1 (SOD1). Recent data has demonstrated increased SOD1 protein levels, yet a marked decrease in enzymatic activity in the Parkinson's disease SN, ${ }^{34}$ proposed to result due to a lack of an essential $\mathrm{Cu}$-association with this protein. Given the key bioactive role for Cu-mediated antioxidant activity in the brain, $\mathrm{Cu}$ modulation is a potential therapeutic avenue for Parkinson's disease ${ }^{59}$ and the repurposed positron emission tomography agent copper(II) diacetylbis(N(4)-methylthiosemi-carbazonato), or $\mathrm{Cu}^{\mathrm{II}}$ (atsm), has shown efficacy in transgenic and neurotoxin mouse models of Parkinson's disease. ${ }^{60}$

The Braak staging scale used to describe the severity of Lewy pathology in the Parkinson's disease brain does not necessarily reflect the more restricted pattern of neuronal loss in this disorder; ${ }^{24}$ nevertheless this method is considered the pathological standard for assessing Parkinson's disease progression and severity. Braak staging refers to the progressive pattern of synucleinopathy deposition which originates in the brainstem and olfactory regions and spreads throughout the brain, classified according to six distinct stages at autopsy. ${ }^{23}$ Lewy pathology is first observed in the SN at stage III, and by stage VI it has spread throughout the neocortex. As post mortem Parkinson's disease cases are typically retrieved at end-stage disease, our analysis was limited to Braak stage V and VI cases. We did not observe any consistent progression in the alterations in $\mathrm{Cu}$ or Fe levels between the two stages, suggesting that metal dyshomeostasis 
within the Parkinson's disease SN occurs during earlier stages of the disease. This is consistent with reports of elevated $\mathrm{Fe}$ and $\mathrm{Cu}$ reductions in the $\mathrm{SN}$ of patients with incidental Lewy body disease ${ }^{8}$ considered a prodromal form of Parkinson's disease. ${ }^{61}$ A larger scale study examining metal levels in the SN and other degenerating, and non-degenerating brain regions, from Parkinson's disease cases representing all six pathologically confirmed Braak stages would assist in determining possible relationships between metal dyshomeostasis and disease progression.

\section{Conclusions}

Although decreased $\mathrm{Cu}$ and elevated Fe levels in the Parkinson's disease SN have been observed in numerous studies over the past few decades, we present here evidence that these changes are primarily present within the soluble component of this primary site of neurodegeneration. Further, no differences between Braak staging indicates that these alterations are likely to occur early in the disease process and are not merely a redistribution of metals within cellular fractions. In line with our previous studies, we postulate that disturbed levels of Fe and $\mathrm{Cu}$ within the Parkinson's disease $\mathrm{SN}$ results in increased oxidative stress from excessive labile $\mathrm{Fe}$, as well as an inadequate cellular response to increased oxidative load by $\mathrm{Cu}$-deficient, dysfunctional cuproproteins. Combined, these two factors may represent key mechanisms contributing to neuronal death, but also practical targets for next-generation therapies.

\section{Author contributions}

SG: designed and performed experiments, analyzed data, wrote drafts of manuscript. BRR: designed experiments. APG: performed experiments. GMH: provided materials support. SJGL: provided materials support. HJB: analyzed data. DJH: designed experiments, analyzed data, wrote and edited manuscript, administered project. KLD: designed experiments, analysed data, wrote and edited manuscript, administered project. All authors read and approved the manuscript.

\section{Conflicts of interest}

B. R. R. and D. J. H. receive material support from Agilent Technologies.

\section{Acknowledgements}

We acknowledge funding from the Victorian Government's Operational Infrastructure Support Program, Parkinson's NSW and the University of Sydney (Biomedical Science, BRIG). DJH is supported by a National Health and Medical Research Council Industry Career Development Fellowship (1122981) in partnership with Agilent Technologies, GMH is the recipient of a National Health and Medical Research Council (Australia) Senior Principal Research Fellowship (1079679). We wish to thank the New South Wales and Sydney Brain Banks, the donors and their families. Tissues were received from the New South Wales Tissue Resource Centre at the University of Sydney supported by the National Health and Medical Research Council of Australia, Schizophrenia Research Institute and the National Institute of Alcohol Abuse and Alcoholism (NIH (NIAAA) R24AA012725) and from the Sydney Brain Bank which is supported by Neuroscience Research Australia, the University of New South Wales and the National Health and Medical Research Council of Australia.

\section{Notes and references}

1 E. L. Que, D. W. Domaille and C. J. Chang, Chem. Rev., 2008, 108, 4328.

2 C. J. Chang, Nat. Chem. Biol., 2015, 11, 744-747.

3 D. T. Dexter, A. Carayon, F. Javoy-Agid, Y. Agid, F. R. Wells, S. E. Daniel, A. J. Lees, P. Jenner and C. D. Marsden, Brain, 1991, 114, 1953-1975.

4 K. J. Barnham and A. I. Bush, Curr. Opin. Chem. Biol., 2008, 12, 222-228.

5 J. Lhermitte, W. M. Kraus and D. McAlpine, J. Neurol. Psychiatry, 1924, 5, 195-208.

6 R. J. Ward, F. A. Zucca, J. H. Duyn, R. R. Crichton and L. Zecca, Lancet Neurol., 2014, 13, 1045-1060.

7 J.-Y. Wang, Q.-Q. Zhuang, L.-B. Zhu, H. Zhu, T. Li, R. Li, S.-F. Chen, C.-P. Huang, X. Zhang and J.-H. Zhu, Sci. Rep., 2016, 6, 36669.

8 K. M. Davies, S. Bohic, A. Carmona, R. Ortega, V. Cottam, D. J. Hare, J. P. M. Finberg, S. Reyes, G. M. Halliday, J. F. B. Mercer and K. L. Double, Neurobiol. Aging, 2014, 35, 858-866.

9 G. Torsdottir, J. Kristinsson, S. Sveinbjornsdottir, J. Snaedal and T. Johannesson, Pharmacol. Toxicol., 1999, 85, 239-243.

10 L. Forsleff, A. G. Schauss, I. D. Bier and S. Stuart, J. Altern. Complement. Med., 1999, 5, 57-64.

11 B. A. Racette, S. Searles Nielsen, S. R. Criswell, L. Sheppard, N. Seixas, M. N. Warden and H. Checkoway, Neurology, 2017, 88, 344-351.

12 D. T. Dexter, P. Jenner, A. H. Schapira and C. D. Marsden, Ann. Neurol., 1992, 32(Suppl), S94-S100.

13 F. A. Zucca, J. Segura-Aguilar, E. Ferrari, P. Muñoz, I. Paris, D. Sulzer, T. Sarna, L. Casella and L. Zecca, Prog. Neurobiol., 2017, 155, 96-119.

14 A. Rembach, J. D. Doecke, B. R. Roberts, A. D. Watt, N. G. Faux, I. Volitakis, K. K. Pertile, R. L. Rumble, B. O. Trounson, C. J. Fowler, W. Wilson, K. A. Ellis, R. N. Martins, C. C. Rowe, V. L. Villemagne, D. Ames, C. L. Masters, AIBL Research Group and A. I. Bush, J. Alzheimers Dis., 2013, 34, 171-182.

15 R. F. Roberts, R. Wade-Martins and J. Alegre-Abarrategui, Brain, 2015, 138, 1642-1657.

16 B. R. Roberts, M. Lind, A. Z. Wagen, A. Rembach, T. Frugier, Q.-X. Li, T. M. Ryan, C. A. McLean, J. D. Doecke, C. C. Rowe, V. L. Villemagne and C. L. Masters, Brain, 2017, 140, 1486-1498. 
17 A. P. Gunn and B. R. Roberts, in Neuromethods - Metals in the Brain: Measurement and Imaging, ed. A. R. White, Springer, New York, 2017, vol. 124, pp. 119-125.

18 B. R. Roberts, J. D. Doecke, A. Rembach, L. F. Yévenes, C. J. Fowler, C. A. McLean, M. Lind, I. Volitakis, C. L. Masters, A. I. Bush and D. J. Hare, Acta Neuropathol. Commun., 2016, 4, 119.

19 M. Comas-Cufí and S. Thió-Henestrosa, CoDaPack 2.0; a stand-alone, multi-platform compositional software, CoDaWork'11: 4th International Workshop on Compositional Data Analysis, Sant Feliu de Guíxols, Spain, 2011.

20 J. Ripp, Analytical Detection Limit Guidance \& Laboratory Guide for Determining Method Detection Limits, Wisconsin Department of Natural Resources, Laboratory Certification Program, 1996.

21 H. J. Motulsky and R. E. Brown, BMC Bioinf., 2006, 7, 1-20.

22 R. A. van den Berg, H. C. Hoefsloot, J. A. Westerhuis, A. K. Smilde and M. J. van der Werf, BMC Genomics, 2006, 7, 142.

23 H. Braak, K. Tredici, U. Rüb, R. de Vos, E. Steur and E. Braak, Neurobiol. Aging, 2003, 24, 197-211.

24 D. J. Surmeier, J. A. Obeso and G. M. Halliday, Nat. Rev. Neurosci., 2017, 18, 101-113.

25 H. Watanabe, J. Senda, S. Kato, M. Ito, N. Atsuta, K. Hara, T. Tsuboi, M. Katsuno, T. Nakamura, M. Hirayama, H. Adachi, S. Naganawa and G. Sobue, Mov. Disord., 2013, 28, 1732-1736.

26 J. Gratwicke, M. Jahanshahi and T. Foltynie, Brain, 2015, 138, 1454-1476.

27 K. M. Davies, D. J. Hare, V. Cottam, N. Chen, L. Hilgers, G. Halliday, J. F. B. Mercer and K. L. Double, Metallomics, 2013, 5, 43-51.

28 L. Zecca, A. Stroppolo, A. Gatti, D. Tampellini, M. Toscani, M. Gallorini, G. Giaveri, P. Arosio, P. Santambrogio, R. G. Fariello, E. Karatekin, M. H. Kleinman, N. Turro, O. Hornykiewicz and F. A. Zucca, Proc. Natl. Acad. Sci. U. S. A., 2004, 101, 9843-9848.

29 L. Zecca, M. Gallorini, V. Schünemann, A. X. Trautwein, M. Gerlach, P. Riederer, P. Vezzoni and D. Tampellini, J. Neurochem., 2001, 76, 1766-1773.

30 S. Ayton, P. Lei, J. A. Duce, B. X. Wong, A. Sedjahtera, P. A. Adlard, A. I. Bush and D. I. Finkelstein, Ann. Neurol., 2013, 73, 554-559.

31 D. T. Dexter, F. R. Wells, A. J. Lee, F. Agid, Y. Agid, P. Jenner and C. D. Marsden, J. Neurochem., 1989, 52, 1830-1836.

32 J. R. Liddell and A. R. White, Neurochem. Int., 2017, DOI: 10.1016/j.neuint.2017.05.016.

33 V. Licker, N. Turck, E. Kovari, K. Burkhardt, M. Cote, M. Surini-Demiri, J. A. Lobrinus, J. C. Sanchez and P. R. Burkhard, Proteomics, 2014, 14, 784-794.

34 B. G. Trist, K. M. Davies, V. Cottam, S. Genoud, R. Ortega, S. Roudeau, A. Carmona, K. De Silva, V. Wasinger, S. J. G. Lewis, P. Sachdev, B. Smith, C. Troakes, C. Vance, C. Shaw, S. Al-Sarraj, H. J. Ball, G. M. Halliday, D. J. Hare and K. L. Double, Acta Neuropathol., 2017, 134, 113-127.

35 K. L. Double, V. N. Dedov, H. Fedorow, E. Kettle, G. M. Halliday, B. Garner and U. T. Brunk, Cell. Mol. Life Sci., 2008, 65, 1669-1682.
36 S. Bohic, K. Murphy, W. Paulus, P. Cloetens, M. Salome, J. Susini and K. Double, Anal. Chem., 2008, 80, 9557-9566.

37 G. M. Halliday, A. Ophof, M. Broe, P. H. Jensen, E. Kettle, H. Fedorow, M. I. Cartwright, F. M. Griffiths, C. E. Shepherd and K. L. Double, Brain, 2005, 128, 2654-2664.

38 V. N. Uversky, J. Neurochem., 2007, 103, 17-37.

39 M. W. Bourassa, H. H. Brown, D. R. Borchelt, S. Vogt and L. M. Miller, Front. Aging Neurosci., 2014, 6, 110.

40 K. J. Barnham and A. I. Bush, Chem. Soc. Rev., 2014, 43, 6727-6749.

41 S. J. Chinta and J. K. Andersen, Biochim. Biophys. Acta, Gen. Subj., 2008, 1780, 1362-1367.

42 E. Deas, N. Cremades, P. R. Angelova, M. Ludtmann, Z. Yao, S. Chen, M. H. Horrocks, B. Banushi, D. Little, M. J. Devine, P. Gissen, D. Klenerman, C. M. Dobson, N. W. Wood, S. Gandhi and A. Y. Abramov, Antioxid. Redox Signaling, 2016, 24, 376-391.

43 D. J. Hare and K. L. Double, Brain, 2016, 139, 1026-1035.

44 T. Terada, M. Yokokura, E. Yoshikawa, M. Futatsubashi, S. Kono, T. Konishi, H. Miyajima, T. Hashizume and Y. Ouchi, Ann. Nucl. Med., 2016, 30, 579-587.

45 E. J. New, Dalton Trans., 2013, 42, 3210-3219.

46 E. L. MacKenzie, K. Iwasaki and Y. Tsuji, Antioxid. Redox Signaling, 2008, 10, 997-1030.

47 S. A. James, I. Volitakis, P. A. Adlard, J. A. Duce, C. L. Masters, R. A. Cherny and A. I. Bush, Free Radical Biol. Med., 2012, 52, 298-302.

48 K. J. Barnham, C. L. Masters and A. I. Bush, Nat. Rev. Drug Discovery, 2004, 3, 205-214.

49 S. J. Guiney, P. A. Adlard, A. I. Bush, D. I. Finkelstein and S. Ayton, Neurochem. Int., 2017, 104, 34-48.

50 D. J. Hare, P. Lei, S. Ayton, B. R. Roberts, R. Grimm, J. L. George, D. P. Bishop, A. D. Beavis, S. J. Donovan, G. McColl, I. Volitakis, C. L. Masters, P. A. Adlard, R. A. Cherny, A. I. Bush, D. I. Finkelstein and P. A. Doble, Chem. Sci., 2014, 5, 2160-2169.

51 D. J. Hare, B. Cardoso, E. P. Raven, K. L. Double, D. I. Finkelstein, E. A. Szymlek-Gay and B.-A. Biggs, $n p j$ Parkinsons Dis., 2017, 3, 1.

52 D. J. Hare, M. Arora, N. L. Jenkins, D. I. Finkelstein, P. A. Doble and A. I. Bush, Nat. Rev. Neurol., 2015, 11, 536-544.

53 R. Niranjan, Mol. Neurobiol., 2014, 49, 28-38.

54 L. M. Collins, A. Toulouse, T. J. Connor and Y. M. Nolan, Neuropharmacology, 2012, 62, 2154-2168.

55 D. Devos, C. Moreau, J. C. Devedjian, J. Kluza, M. Petrault, C. Laloux, A. Jonneaux, G. Ryckewaert, G. Garçon, N. Rouaix, A. Duhamel, P. Jissendi, K. Dujardin, F. Auger, L. Ravasi, L. Hopes, G. Grolez, W. Firdaus, B. Sablonnière, I. StrubiVuillaume, N. Zahr, A. Destée, J.-C. Corvol, D. Pöltl, M. Leist, C. Rose, L. Defebvre, P. Marchetti, Z. I. Cabantchik and R. Bordet, Antioxid. Redox Signaling, 2014, 21, 195-210.

56 D. Hare, S. Ayton, A. Bush and P. Lei, Front. Aging Neurosci., 2013, 5, 34.

57 T. Moos, T. R. Nielsen, T. Skjorringe and E. H. Morgan, J. Neurochem., 2007, 103, 1730-1740. 
58 G. Grolez, C. Moreau, B. Sablonniere, G. Garcon, J. C. Devedjian, S. Meguig, P. Gele, C. Delmaire, R. Bordet, L. Defebvre, I. Z. Cabantchik and D. Devos, BMC Neurol., 2015, 15, 74.

59 K. M. Davies, J. F. B. Mercer, N. Chen and K. L. Double, Clin. Sci., 2016, 130, 565-574.

60 L. W. Hung, V. L. Villemagne, L. Cheng, N. A. Sherratt, S. Ayton, A. R. White, P. J. Crouch, S. Lim, S. Leong, S. Wilkins, J. George, B. R. Roberts, C. Pham, X. Liu,
F. Chiu, D. M. Shackleford, A. K. Powell, C. L. Masters, A. I. Bush, G. O'Keefe, J. G. Culvenor, R. Cappai, R. A. Cherny, P. S. Donnelly, A. F. Hill, D. I. Finkelstein and K. J. Barnham, J. Exp. Med., 2012, 209, 837-854.

61 D. W. Dickson, H. Fujishiro, A. DelleDonne, J. Menke, Z. Ahmed, K. J. Klos, K. A. Josephs, R. Frigerio, M. Burnett, J. E. Parisi and J. E. Ahlskog, Acta Neuropathol., 2008, 115, 437-444. 